\title{
The First Annual Meeting of the Society for Neuroscience, 1971: Reflections Approaching the 50th Anniversary of the Society's Formation
}

\author{
R. Douglas Fields \\ National Institutes of Health, National Institute of Child Health and Human Development, Bethesda, Maryland 20904
}

The formation of the Society for Neuroscience in 1969 was a scientific landmark, remarkable for the conceptual transformation it represented by uniting all fields touching on the nervous system. The scientific program of the first annual meeting of the Society for Neuroscience, held in Washington, DC in 1971, is summarized here. By reviewing the scientific program from the vantage point of the 50th anniversary of the Society for Neuroscience, the trajectory of research now and into the future can be tracked to its origins, and the impact that the founding of the Society has had on basic and biomedical science is evident. The broad foundation of the Society was firmly cast at this first meeting, which embraced the full spectrum of science related to the nervous system, emphasized the importance of public education, and attracted the most renowned scientists of the day who were drawn together by a common purpose and eagerness to share research and ideas. Some intriguing areas of investigation discussed at this first meeting blossomed into new branches of research that flourish today, but others dwindled and have been largely forgotten. Technological developments and advances in understanding of brain function have been profound since 1971, but the success of the first meeting demonstrates how uniting scientists across diversity fueled prosperity of the Society and propelled the vigorous advancement of science.

\section{Introduction}

Before the formation of the Society for Neuroscience ( $f f N$ ), in 1969 , research concerning the nervous system was conducted in several separate scientific disciplines, including anatomy, physiology, psychiatry, psychology, neurology, and zoology, but the concept that all of these pursuits could be combined into one coherent new field of science was revolutionary. The history of the formation of the $\mathrm{S} f \mathrm{~N}$ has been reviewed elsewhere (see The Creation of Neuroscience, Society for Neuroscience, 2018), but the scientific program of that first meeting is a time capsule preserving the state of brain science at a pivotal point in history. The pioneering neuroscientists meeting in 1971 grappled with many of the most fundamental issues in brain function at a time of comparatively rudimentary techniques and limited understanding of the brain. In the fullness of time, it is now possible to see retrospectively how the early evidence available, some of it presented at this meeting, was misinterpreted and projected into new grand hypotheses that were constrained and misdirected by the limited information available at the time. Today, the field of neuroscience has grown into one of the most vigorous areas of biomedical research, spanning broadly from mathematical modeling, to molecular, cellular, systems,

Received July 27, 2018; revised Sept. 5, 2018; accepted Sept. 7, 2018.

This work was supported by National Institute of Child Health and Human Development ZIAHD000713-22 (funds for intramural research).

The author declares no competing financial interests.

Correspondence should be addressed to Dr. R. Douglas Fields, National Institutes of Health, National Institute of

Child Health and Human Development, Building 9, Room 1E126, MSC 0905, Bethesda, MD 20904. E-mail: fieldsd@mail.nih.gov.

DOI:10.1523/JNEUROSCI.3598-17.2018

Copyright $\odot 2018$ the authors $\quad 0270-6474 / 18 / 389311-07 \$ 15.00 / 0$ and behavioral levels, but all of these scientific elements of what we now recognize as "neuroscience" were represented at that first meeting.

This review article provides a synopsis and analysis of neuroscience research presented at the first annual meeting. Held in the age of typewriters, there is no digital copy of the first annual meeting program, but a personal copy of the blue, 288-page, program booklet bearing the inked stamp and signature of Alan D. Grinnell, Department of Biology at University of California, Los Angeles on the cover, was preserved in the archives at the Sf $\mathrm{N}$ headquarters in Washington, DC. Grinnell is well known for his research on synaptic transmission, notably at the neuromuscular junction, and fortunately his personal copy of the Program and Abstracts of that first meeting survives (Fig. 1).

\section{The beginning of $S f \mathrm{~N}$ annual meetings}

The first Annual Meeting was held on October 27-30, 1971, at the Shoreham Hotel in Washington, DC. The registration fee was $\$ 20.00$ for members and $\$ 5.00$ for students. Adjusted for inflation, $\$ 20$ would be $\$ 126$ today (Bureau of Labor Statistics, 2018). The more than quadrupled registration cost of $\$ 550$ for the 2018 Annual Meeting might reflect in part the enormous success of the Society, which has grown so large its gatherings can only be accommodated at the largest convention centers in the country, drawing on all hotels in the vicinity for housing during the weeklong annual event (Fig. 2). In contrast, that first meeting was an intimate gathering of 1395 scientists, including 390 students, held in one hotel, where everyone could interact over the course of 3 days. "You could go to everything," David Lange, an electro- 


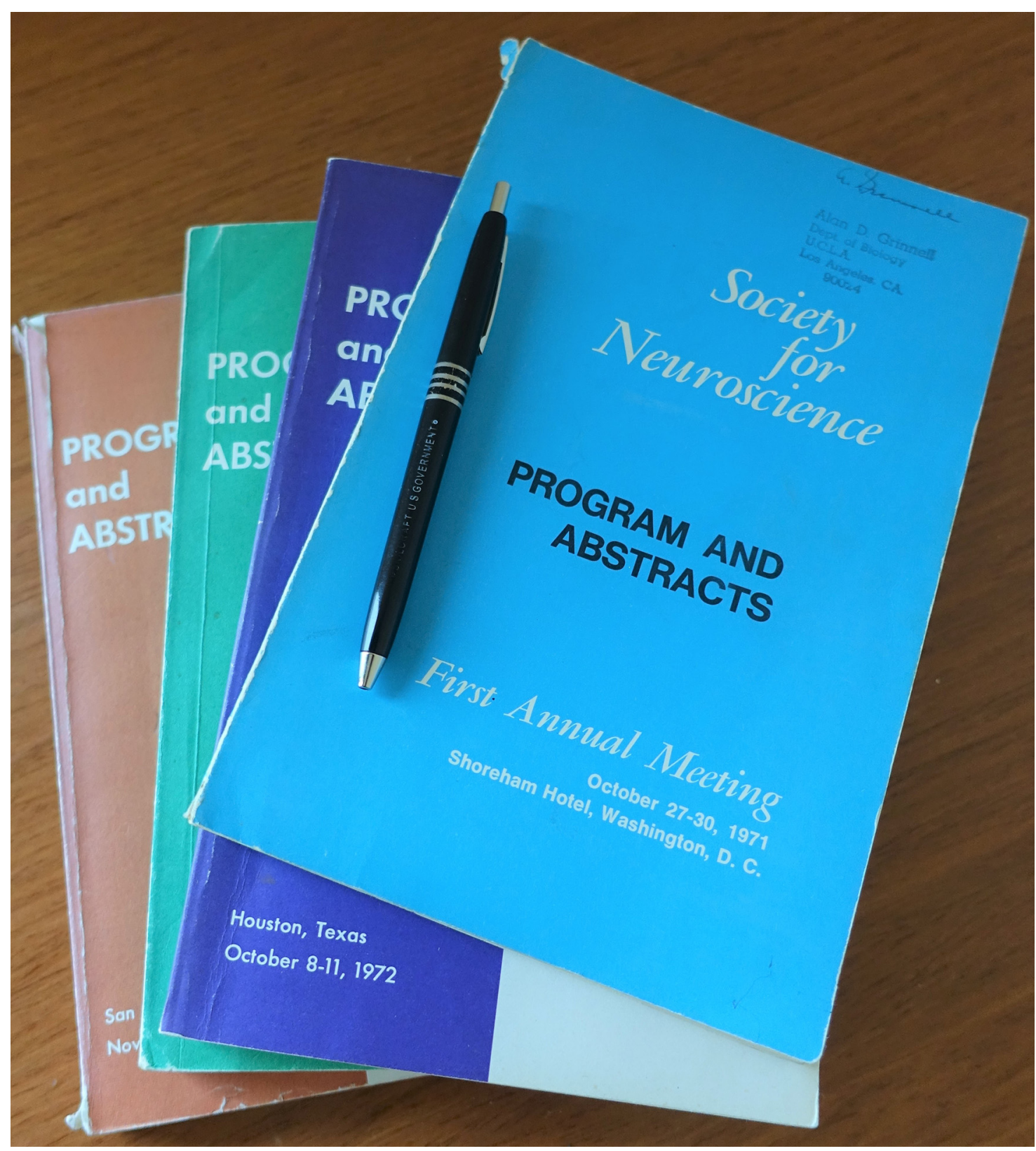

Figure 1. Program booklets for the first four Sf N Annual Meetings. The first annual meeting was held in 1971, in Washington, DC.

physiologist at National Institute of Neurological Disorders and Stroke, now retired, recalled about that first meeting.

It is notable that this first annual meeting included a press room, welcoming journalists to promote research on the brain to the general public. Today, the press room at the annual meeting is abuzz with 300 registered journalists from around the world, furiously typing up newspaper and magazine articles on laptops, others with microphone in hand and wearing headphones recording TV and radio interviews with scientists, and attending well-organized press conferences where leading scientists in "hot topic" areas of research are invited in a panel discussion to present their latest findings directly to the press. Likewise, it is notable that this first meeting devoted one morning session to education. A belief in promoting understanding of neuroscience in medical, graduate, and undergraduate education was one of the prime reasons for forming the $\mathrm{S} f \mathrm{~N}$, and the mission of academic and public education about brain science remains paramount.

\section{Synopsis of the first sessions}

There were two types of sessions at this first meeting: long format Selected Topics Seminars, held for 2.5 hours in the morning, and short Contributed Papers grouped thematically and held in the afternoons (Table 1). The Contributed Papers sessions in the afternoons resembled the short talks in nanosymposia at today's Annual Meeting, but the Selected Topic Sessions varied widely in format, mixing together what would be considered Special Lectures, Symposia, and nanosymposia today. Typically, each Selected Topics Seminar session included one or two Introductory Lectures by luminaries in the field, typically followed by a few shorter contributed papers related to that research topic, and sometimes closed by a Summarizing Lecture, but some of the Selected Topic Sessions were comprised entirely of three Invited lectures by leading neuroscientists, and others were all short, $\sim 10$ min presentations of Selected Contributed Papers that pertained to topic of the session. 


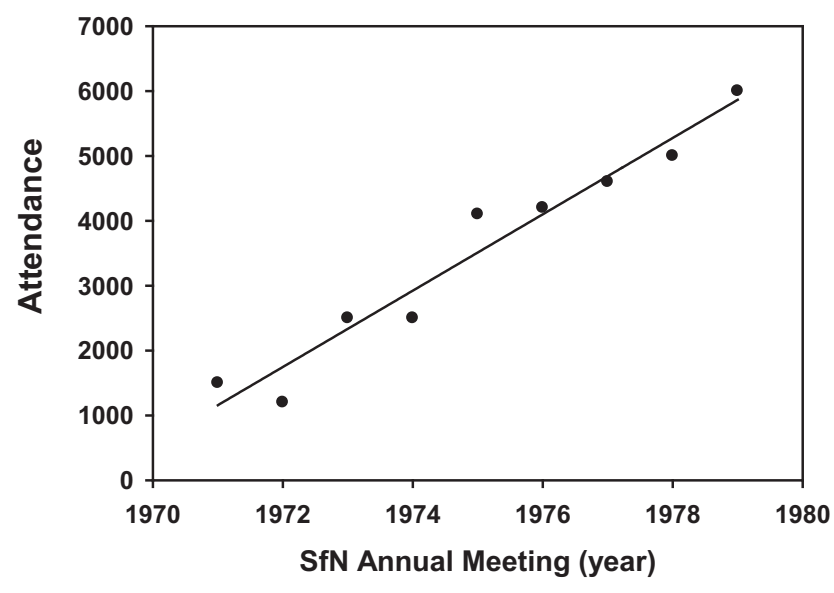

Figure 2. Attendance at $S f \mathrm{~N}$ Annual Meetings in the years immediately after the first meeting in 1971, showing a consistent steep rise in attendance, which averages $\sim 30,000$ attendees today (http://www.brainfacts.org/Home/SfN/Annual-Meeting/Past-and-Future-Annual-Meetings/ Annual-Meeting-Attendance-Statistics). Data before 1979 are replotted from Joel Braslow (https:// www.sfn.org/About/History-of-SfN/1969-1995/Chapter-3).

Three Selected Topics Sessions that focused on different subject areas were held simultaneously in the mornings, and 9 or 10 Contributed Papers sessions were held simultaneously in the afternoons. All the presentations were held in rooms in close proximity within the same hotel, so attendees could easily pass from room-to-room to attend any talk they wished.

The first scientific presentation at the first $S f \mathrm{~N}$ meeting was Chaired by Vernon Mountcastle, of Johns Hopkins University School of Medicine, in a session on psychophysics, entitled Sensation and Perception: Psychophysical Measurements and Brain Mechanics, and Mountcastle delivered the second Introductory Lecture on Neural Mechanisms in Sensation, and the Linearity of the Action of the Nervous System, research that today might be called computational neuroscience or neural coding. Neuroscientist Terrence Sejnowski described Mountcastle as "the father of neuroscience" in an obituary for Mountcastle, published in 2015 (Sejnowski, 2015). Mountcastle was the first elected president of the fledgling society; and according to Sejnowsky, Mountcastle "planned every detail of the inaugural meeting and was at the front door to greet everyone into what would eventually become a major scientific discipline.” During his career, Mountcastle pioneered electrophysiological recording from single neurons in the somatosensory system. He quantified the action potential firing thresholds and firing rates of neurons in response to sensory stimulation, to correlate with the perceptual experiences produced, and he described, for the first time, the columnar organization of the cerebral cortex.

Unfortunately, in contrast to the shorter Contributed Papers, there were no printed abstracts of the Invited Lectures. This is unfortunate because the invited lectures were given by some of the most renowned brain scientists of the day, many of whom remain current leaders in the field; among these were John Eccles, Walle Nauta, Floyd Bloom, Dominick Purpura, Stephen Kuffler, Michael Gazzaniga, and many others. See the autobiographies of many of these and other pioneering neuroscientists in The History of Neuroscience in Autobiography (Albright and Squire, 2016).

Three short talks on related research followed the Introductory Lectures in this session, and, as with all Contributed Papers, abstracts of the talks were printed in the program. One of these concerned the relationship between cooling the skin and the sub- jective intensity discrimination, and another described a study on the intensity and wavelength of light in vision. This session was held while two other Selected Topics Seminars on Molecular Mechanisms and Critical Periods in CNS Development were being held in nearby rooms.

One of the talks in the morning session on psychophysics, in contrast to the others, which were performed on human subjects, reported experiments by Stanford Psychologist, Karl Pribram and colleagues, on slow cortical potentials recorded in the rhesus monkey performing a learned task. The purpose here is not to dwell on Pribram's research specifically, but rather to use research presented at this first meeting to give the flavor of the status of brain research at the formation of the $S f \mathrm{~N}$, and to see from a current vantage point how research of that era has developed.

Pribram devoted his career to studying in humans and nonhuman primates what is today called systems neuroscience, which is the study of complex electrophysiological and anatomical interactions among different parts of the brain to produce perceptions, motor outputs, emotions, and behavior. In contrast to the textbook concept of the sequential progression of sensory input from simple feature detection in primary sensory cortex to complex, multimodal interactions in association cortex and frontal cortex, Pribram documented the reciprocal transmission of information from higher cortical regions to primary sensory cortex and subcortical regions, demonstrating how sensory perception, emotion, and even autonomic function can be regulated by descending input from higher cortical regions.

This holistic view of the brain as a complex, highly integrated global network stood in contrast to the equally valid, but reductionist, view of neural function gleaned from the investigation of feature detectors and cortical columns being pioneered by researchers, such as Mountcastle and Nobel Laureates, David Hubel, and Torsten Weisel. But Pribram was a postdoctoral fellow of psychologist, Karl Lashley, whom after decades of attempting to discover where in the brain memories are recorded (the engram), admitted defeat in 1950, concluding that the memory trace did not exist at any one place in the brain (Lashley, 1950). Lashley reached this conclusion after years of training rats and other animals to run a maze or perform some other learning test, and then systematically removed different cortical regions, but he found that the animal still retained the learned information, with the deficit proportional to the amount of cortex removed. Memories were not stored somewhere in the brain; they were stored everywhere.

The brain had to operate by a much more globally integrated, complex system. For example, how could a feature detector, such as a neuron responding to a bar of light moving in one orientation, form an integrated image that assigned the correct edges to objects, together with their motion, and other features, to produce a discrete object in the mind as, for example, when a familiar person's face approaches and the image of the entire visual scene streaks across the retina? Where does the person's face stop and a hat on the head begin, unless somehow all the features of the scene were being analyzed globally, simultaneously, and instantaneously, to make this determination?

Experiments of the type that Pribram reported in this session, while recording electrical waveforms from visual cortex of monkeys after they were trained to respond to an object presented on the screen, enabled him to discern from the evoked brainwave response alone which visual object in a choice-type experiment the animal was perceiving; that is, to see the animal's perception of the world in the electrical activity flowing through its cortex. 


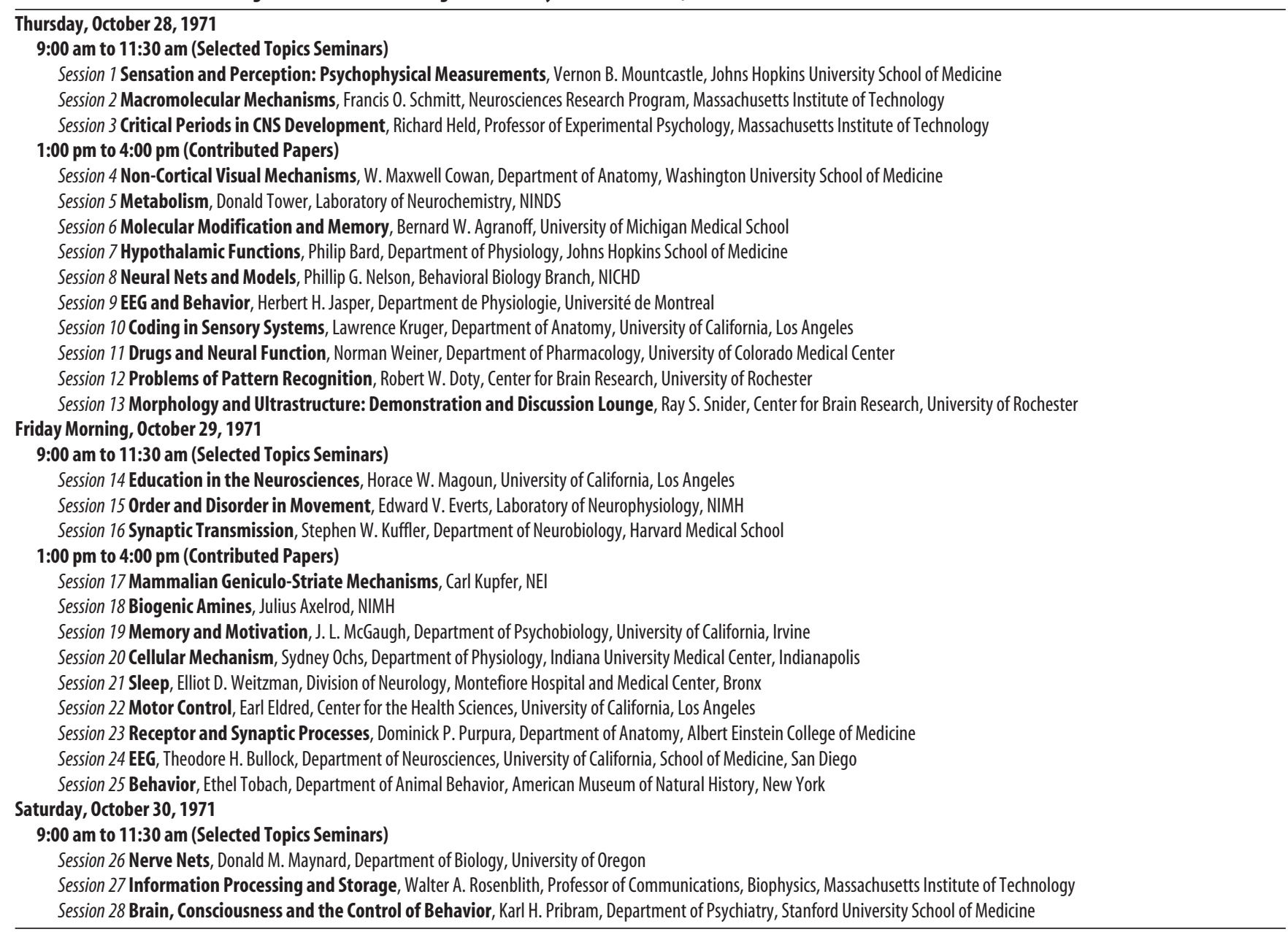

Moreover, the monkey's intended response in a choice-type experiment was revealed in each trial, simply by the waveform, and this insight was made even before the monkey executed its choice. The shape of the cortical waveform response also indicated whether the monkey had made the correct or incorrect choice. These distinctive ripples of ongoing electrical activity in the cerebral cortex revealed a highly complex and integrated information processing ongoing in the brain while an animal thinks and behaves. "What we see is not a pure and simple coding of the light patterns that are focused on the retina," he wrote in a 1969 Scientific American article about this line of research. "Somewhere between the retina and the visual cortex the inflowing signals are modified to provide information that is already linked to a learned response, for example the monkey's intention to press one panel or another" (Pribram, 1969).

Such issues are very much at the forefront of neuroscience today, with techniques, such as EEG and ECoG, being used to monitor brain activity to detect behavioral intentions and to operate prosthetic devices. This approach, adopted at the earliest point in history when the appropriate technology became available, has now blossomed into the modern "connectomics" gestalt view of brain function, which is being actively promoted by the BRAIN initiative, a new National Institutes of Health funding program that provides support for development of new technologies to monitor neuronal function and anatomy in the brain on a global scale.

But how could the brain perform this instantaneous global recording and retrieval of information, which spans throughout the entire cerebral cortex? Even now, this question remains a mystery. After reading an article on holography in Scientific American, Pribram conceived the idea that the brain operated like a hologram, in which information was widely distributed and could be accessed even by a fragmentary portion of the hologram, just as Lashley had found an animal could recall a memory even after removing bits of its cerebral cortex (Pribram and Carlton, 1986; Jibu et al., 1994). Using hologram not only as metaphor, but rather as mechanism, Pribram speculated that electrical wave fronts produced by multiple synaptic inputs converging onto a target neuron could interact destructively and constructively to filter, combine, and extract information holographically.

The afternoon sessions on that first day of the meeting were no less profound in that researchers were boldly confronting some of the deepest mysteries of how the brain operates. Central issues, such as the mechanism of memory and consciousness, which still challenge us today, were confronted.

\section{Remembering and forgetting sensational research on memory}

A good example of research at the cutting edge of science, which were hot topics of the day that flourished productively and continue today, intermixed with other research that fizzled out and became largely forgotten in the light of new understanding, is the afternoon session that was Chaired by Bernard W. Agranoff, University of Michigan Medical School, on Molecular Modification and Memory. Agranoff is a distinguished neuroscientist whose work began to reveal how learning and memory operate at a 
molecular level. The results of this line of research led several scientists to concluded that memory must be recorded in the sequence of molecules in strands of RNA and/or protein. The 1960s and early 1970s was the dawn of the age of molecular biology, which burst forth after Watson and Crick's discovery in 1953 of the structure of DNA and Marshall Nirinberg's determination that genetic information was coded in the sequence of nucleic acids specifying the order of amino acids in proteins. If all the information required to produce an organism from conception to manage its daily operation throughout life, and to record all the significant evolutionary experiences over eons could be recorded in a sequence of DNA, RNA, and amino acids, then why not also the daily experiences of life, memory, be recorded by the same molecular biology?

This concept for how memory worked at a cellular level was not simply speculation; it was based on interpretation of new experimental evidence. It was a revolutionary approach at the time to incorporate biochemistry into brain science; biochemistry was completely outside the bounds of electrophysiology, neurology, psychology, and anatomy at the time. Pioneering experiments on a wide range of animals in various learning tasks showed that learning and experience did indeed produce biochemical changes in neurons, and that interfering with these biochemical events did impair learning and memory. Agranoff trained goldfish in a shuttle box aquarium to swim to the opposite side of the tank when a light was turned on to avoid an electrical shock. The fish became conditioned to the light and darted to the other side when it was flashed even before the punishing shock was delivered. However, injecting puromycin, a protein synthesis inhibitor, into the brain of goldfish impaired the memory of the shock-avoidance response (Agranoff and Klinger, 1964; Agranoff and Davis, 1967). He and his colleagues showed further that injection of actinomycin D, an inhibitor of RNA transcription, also interfered with memory (Agranoff et al., 1967). Larry Squire and Samuel Barondes, of the University of California, San Diego, extended these findings to mice, reporting in the same session that the protein synthesis inhibitor cycloheximide blocked learning in mice, and that development of amnesia depended on when the drug was given during training. Through such biochemical interventions, as well as other interventions such as electroshock, which also surprisingly altered brain chemistry, researchers began to separate memory formation and retrieval into discrete steps of short-term, long-term memory acquisition, consolidation, and recall.

Further experiments by several researchers extended these biochemical studies on encoding of memories into molecules and found that learned experience could be transmitted between animals by transferring the appropriate molecules that had recorded the learned experiences. After training an animal, crude brain extract, RNA, or protein (depending on the particular study) could be extracted from the trained animal and injected into the brain of a naive recipient animal, and the knowledge would be transferred. This memory transfer research was replicated in many different animals, in many laboratories, and published in the highest profile journals, Nature (Ungar and Ocequera-Navarro, 1965; Rosenblatt et al., 1966; Jacobson et al., 1966; Ungar and Irwin, 1967; Reinis and Kolousek, 1968; Malin et al., 1971; Bisping et al., 1974) and Science (Babich et al., 1965; Braud, 1970; Golub et al., 1970; Braud and Braud, 1972), and in more specialized journals. (The Society's Journal of Neuroscience was not launched until 1981.) Agranoff's work showed the necessity of transcription and translation in forming long-term memory, but he did not extrapolate beyond this to conclude that memory was recorded in nucleotide or amino acid sequences and could be transferred between brains. This view, however, was supported by many. William Braud, Department of Psychology, University of Houston, reported in this session his experiments in which RNA-protein extracts prepared from whole brains of goldfish trained in the shuttle box and injected into naive goldfish, transferred the memory of this task, and Ronald Hoffman, Department of Biophysical Science at the University of Houston, reported in his talk his success in transferring learned behavior by injecting brain extracts from goldfish trained to discriminate between upright and inverted triangles into the brains of naive goldfish.

Memory transfer experiments began with studies on a flatworm, Planaria, by James V. McConnell of the University of Michigan. Planaria are capable of extensive regeneration. If a worm is cut in half across the midsection, the head segment will regenerate a new tail and the tail segment will regenerate a new head. The stunning finding by McConnell and others was that the worm formed from the tail stump that regenerated a new head retained the learned knowledge, a conditioned reflex to respond to a light, that the worm had learned before being sliced in half. How could this "daughter" worm, forming an entirely new brain, retain learned knowledge unless the memory was somehow recorded throughout the body? The most reasonable supposition was that a biochemical code had stored the memory and the new brain used it.

Further proof came from the biological fact that these worms have a penchant for cannibalizing one another. McConnell and colleagues found that memory of a trained Planarian could be transplanted into a naive Planarian by feeding the recipient flatworm the body of a flatworm that had been trained in a conditioned reflex experiment (McConnell, 1962; Kartry et al., 1964).

This memory transfer research, and the concept that memories are recorded in molecules, gripped the general public through a flurry of science news articles and even by McConnell appearing on the Steve Allen, late-night TV program. The futuristic prospect that it soon would be possible to dispense with the arduous labor of learning a new language and acquire the knowledge easily through a pill or injection, created a sensation. High school students began to do science projects on memory transfer (McConnell, 1965). I was one of them. I studied Agranoff's Scientific American article (Agranoff, 1967) and managed to train goldfish and later rats, but my experiments "failed" in transferring the memory by injecting the RNA from the trained animal's brain into the untrained animal. It was this science project that sparked my interest in how memories are stored and launched my career in neuroscience. To the extent that the $S f \mathrm{~N}$ engages journalists in an effort to widen appreciation, wonder, and understanding of brain science among the general public, and to inspire the next generation of neuroscientists, I offer my personal experience as one among many examples.

Unfortunately, notoriety can present certain perils. James McConnell became one of the targets of Ted Kaczynski, the Unibomber. When the package bomb addressed to him exploded in 1985, he was lucky, suffering only some hearing loss, but his assistant Nicklaus Suino, age 25, was wounded (Lardner and Adams, 1996).

This early episode in memory research is highly relevant to the current "crisis" of reproducibility in science, arising from the alarming number of papers being retracted or found to be unsound. What exposed the memory transfer research as being erroneous was the Scientific Method. As other researchers attempted and failed to replicate the earlier experiments, the findings and interpreta- 
tions of memory transfer studies came into question (Gross and Carey, 1965; Byrne et al., 1966; Luttges et al., 1966; Yaremko and Hillix, 1973). Soon, advances in knowledge rendered the memory transfer work as incorrect and incompatible with new facts and knowledge. The molecular changes detected after learning are now cogently fitted into our greater understanding of transcription factors, epigenetic markers, intracellular signaling, and detailed understanding of how experience alters neuronal and synaptic function. Not only the misinterpretation of the early data, but also the data itself are now clearly revealed as being wrong, and corrupted by bias and lack of proper controls. It is debatable whether the new accounting measures that scientific journals are now demanding with the aim of increasing scientific reproducibility would have prevented these memory transfer experiments from being published, but there is no doubt that the self-correcting nature of the Scientific Method will, in time, find its way to the truth.

The researchers who advanced such hypotheses, which now seem wild, cannot be faulted because the necessary scientific knowledge, techniques, and ideas required to properly interpret the limited experimental evidence of the day were lacking; indeed, it was years or decades away. Thus, these early tantalizing clues from experiments on the brain could not possibly be incorporated correctly to reach what we now see as the correct conclusion. One of the most valuable lessons from examining this scientific history is the queasy realization that this situation always exists at the forefront of science. How naive will some of our present ideas, hypotheses, and conclusions about brain function today - perhaps ones that are even highlighted at the current $\mathrm{S} f \mathrm{~N}$ meeting - appear in retrospect after neuroscience and other fields of science advance to enable us to properly comprehend early clues that we are now uncovering, which are being misinterpreted and leading investigators off into blind alleys?

\section{Days 2 and 3}

It is not possible, or even desirable, to provide a detailed synopsis of every session at the meeting, even to the extent that the first day has been recounted here. The purpose is to capture the historical moment and distill some of the most salient features with the benefit of a 50 year hindsight. Days 2 and 3 of the meeting will, therefore, be summarized in less detail. The second day of the first $\mathrm{S} f \mathrm{~N}$ Annual meeting, Friday, began with a morning session that was devoted to education in the neurosciences, and it was open to the public. The session opened with an introductory lecture by Dominick Purpura, Albert Einstein College of Medicine, followed by a contributed paper by Louise Marshall of the National Research Council on Neuroscience for Medical Students. These presentations were followed by a panel discussion on interdisciplinary education in neuroscience, precollege through postdoctoral levels, demonstrating the commitment of the Society to education in neuroscience. The two other sessions held at the same time were on Movement Disorders and Synaptic Transmission (Table 1).

Friday afternoon had 8 sessions of Contributed Papers. Spanning research on memory, vision, biogenic amines, cell biology, sleep, motor control synaptic receptors, behavior, and EEG, the latter session chaired by the Society's third elected President (1973-4), Theodore Bullock. The EEG session spanned seizure to lesion studies, as well as behavioral correlates (breath holding, reaction time, and emotional behavior). In the behavioral session, research on electrical brain stimulation and self-stimulation of the brain, early postnatal experience effects on brain biochem- istry, split brain effects, and escape training in paramecia were presented.

The final day, Saturday morning, had three concurrent sessions: Nerve Nets, Information Processing and Storage, and Consciousness and Control of Behavior. The latter included lectures by John Eccles, Laboratory of Neurobiology, University of New York at Buffalo, Walle Nauta, Department Psychology, Massachusetts Institute of Technology, and Edward Evarts, Laboratory of Neurophysiology, National Institute of Mental Health, but no Contributed Papers.

\section{Then and now}

What we now know as neuroscience could just as easily have remained fractionated into separate disciplines, each with its own society and separate meetings, with no unifying organization or annual meeting. If that had occurred, one wonders how our present understanding of the brain might be different today. The challenge of understanding the brain, mind, behavior, and dysfunction cannot be met without bringing to bear the full arsenal of scientific power and technology in an attempt to comprehend it, from mathematics to psychology. This active and deliberate collaboration that was conceived by the visionaries who came together to form the $\mathrm{S} f \mathrm{~N}$ in 1969 and organize that first Annual Meeting in 1971 propelled the advancement of science and demonstrated how to achieve sweeping progress in science. Part of that commitment to inclusion was the recognition that science in the 1960s and early 1970s was entirely dominated by men. The second annual meeting, held in Houston, in 1972, instituted a Women's Hospitality Room, to accommodate spouses of scientists, and provide a place for women to relax and socialize during the day. Today this could be viewed cynically as a quaint and politically incorrect thing to do, but in its day it was a sincere effort to begin to bring women into what had previously been an exclusively male domain. It was a start, in my view, and the Society has continued to work to increase participation of women and underrepresented groups in the Society and its meetings. Great progress has been made, and the membership and science are the beneficiaries, while recognizing that there is much more that needs to be done to bring the best minds together to collaborate scientifically.

Apart from the obvious differences arising from tremendous technical advances since 1971, the diversity of animal models used at this first meeting is striking. Comparative zoology was one of the most insightful means of investigating the nervous system before the advent of transgenic and knock-out mice, immunocytochemistry to identify specific proteins, gene sequencing, and MRI to do structural and functional studies noninvasively in humans. In addition to human subjects, research presented at this first meeting was a veritable Noah's ark of the animal kingdom: orb web spider, crayfish antennae, electric fish, cats, rat, kangaroo rat, raccoon, pigeons, dog, mouse, shark, frog, opossum, squid, octopus, goldfish, monkeys, paramecia, flatworms, ground squirrel, goldfish, lamprey, locusts, and guinea pig. Research on nonhuman primates and other models that were common at this first meeting is becoming increasingly limited. The National Institutes of Health will no longer support experimental research on chimpanzees, for example, and similar bans have been instituted in other countries (Kaiser, 2015). Rodents, especially transgenic mice, are powerful preparations for experimental research on the brain, but as with all models, they have limitations. The rat heart may be a good model for the human heart; the rat brain is a feeble model for the human brain. The human brain excels in complexity and function incomparably 
beyond the brain of all other animals. Glial (Oberheim et al., 2009) and neuronal cells (Boldog et al., 2018) that are unique to humans have been identified. Treatments for neurological disorders that are effective in rodents, spinal cord injury to cite one example, can often disappoint when tested in clinical trials on humans. Noninvasive brain imaging and the resurgence of brain stimulation are energizing a new field of research on human brain function, but elucidating the cellular and molecular mechanisms will require animal models, and the more complex, "human-like" cognitive and behavioral functions, which are of greatest interest to mankind, may not be applicable to other organisms. Myelin, for example, which may be involved in learning (Fields, 2015), does not exist in invertebrates, and there will always be uncertainty about the extent to which a mouse or a rat experiences schizophrenia or any number of other human mental disorders.

The enormous growth and success of the annual meetings are not without complications. In the early years, the meetings included anatomical, physiological, and behavioral demonstrations that were open to the public. At the third annual meeting held in 1973 in San Diego, Special Interest Dinners were organized after the evening public lecture, where people sharing common scientific interests met for dinner at "reasonably priced local restaurants," in which leaders of the field shared a meal and conversation with anyone who was interested. Such an open dinner invitation to the entire Society would be impossible today, but these were the forerunners of the current $\mathrm{S} f \mathrm{~N}$-sponsored socials now held two evenings during the annual meetings. Today many complain that the $\mathrm{S} f \mathrm{~N}$ meeting is like drinking from a firehose, with too many concurrent sessions, spread across great distances in enormous convention centers, with crowds of people so thick in the poster sessions that it is sometimes impossible to thread through the throng to see some posters or hear what is said through the deafening din. Still, the latest results from around the world on nervous system function will be presented at the annual meetings. While you can no longer "Go to everything," as David Lange remembered from that first meeting, "everyone" will be there; and for these reasons, thousands of neuroscientists and students from around the world will continue to flock to the $S f \mathrm{~N}$ Annual Meetings every fall.

\section{References}

Agranoff BW (1967) Memory and protein synthesis. Sci Am 216:115-122. CrossRef Medline

Agranoff BW, Davis RE (1967) Further studies on memory formation in the goldfish. Science 158:523. CrossRef Medline

Agranoff BW, Klinger PD (1964) Puromycin effect on memory fixation in the goldfish. Science 146:952-953. CrossRef Medline

Agranoff BW, Davis RE, Casola L, Lim R (1967) Actinomycin D blocks formation of memory of shock-avoidance in goldfish. Science 158:16001601. CrossRef Medline

Albright TL, Squire LR (2016) The history of neuroscience autobiography, Society for Neuroscience. Available through open access on the $S f \mathrm{~N}$ website: https://www.sfn.org/about/history-of-neuroscience/autobiographicalchapters.

Babich FR, Jacobson AL, Bubash S, Jacobson A (1965) Transfer of a response to naive rats by injection of ribonucleic acid extracted from trained rats. Science 149:656-657. CrossRef Medline

Bisping R, Benz U, Boxer P, Longo N (1974) Chemical transfer of learned colour discrimination in goldfish. Nature 249:771-773. CrossRef Medline

Boldog E, Bakken TE, Hodge RD, Novotny M, Aevermann BD, Baka J, Bordé S, Close JL, Diez-Fuertes F, Ding SL, Faragó N, Kocsis ÁK, Kovács B, Maltzer Z, McCorrison JM, Miller JA, Molnár G, Oláh G, Ozsvár A, Rózsa
M, et al. (2018) Transcriptomic and morphophysiological evidence for a specialized human cortical GABAergic cell type. Nat Neurosci 21:11851195. CrossRef Medline

Braud LW, Braud WG (1972) Biochemical transfer of relational responding (transposition). Science 176:942-944. CrossRef Medline

Braud WG (1970) Extinction in goldfish: facilitation by intracranial injection of RNA from brains of extinguished donors. Science 168:1234-1236. CrossRef Medline

Bureau of Labor Statistics (2018) Available at https://www.bls.gov/data/ inflation_calculator.htm.

Byrne WL, Samuel D, Bennett EL, Rosenzweig MR, Wasserman E, Wagner AR, Gardner F, Galambos R, Berger BD, Margules DL, Fenichel RL, Stein L, Corson JA, Enesco HE, Chorover SL, Holt CE III, Schiller PH, Chiapetta L, Jarvic ME, Leaf RC, et al. (1966) Memory transfer. Science 153: 658-659. CrossRef Medline

Fields RD (2015) A new mechanism of nervous system plasticity: activitydependent myelination. Nat Rev Neurosci 16:756-767. CrossRef Medline

Golub AM, Masiarz FR, Villars T, McConnell JV (1970) Incubation effects in behavior induction in rats. Science 168:392-395. CrossRef Medline

Gross CG, Carey FM (1965) Transfer of learned response by RNA injection: failure of attempts to replicate. Science 150:1749. CrossRef Medline

Jacobson AL, Fried C, Horowitz SD (1966) Planarians and memory. Nature 209:599-601. CrossRef Medline

Jibu M, Hagan S, Hameroff SR, Pribram KH, Yasue K (1994) Quantum optical coherence in cytoskeletal microtubules: implications for brain function. BioSystems 32:195-209. CrossRef Medline

Kaiser J (2015) An end to U.S. chimp research. Science 350:1013. CrossRef Medline

Kartry AL, Keith-Lee P, Morton WD (1964) Planaria: memory transfer through cannibalism reexamined. Science 146:274-275. CrossRef Medline

Lardner G, Adams L (1996) To Unabomb victims, a deeper mystery. Washington Post, April 14, 1996, p A01. https://www.washingtonpost.com/ wp-srv/national/longterm/unabomber/bkgrdstories.victims.htm.

Lashley K (1950) In search of the engram. Symp Soc Exp Biol 4:454-482.

Luttges M, Johnson T, Buck C, Holland J, McGaugh J (1966) An examination of "transfer of learning" by nucleic acids. Science 151:834-837. CrossRef Medline

Malin DH, Golub AM, McConnell JV (1971) Effect of an RNA-rich extract on acquisition of a one-way avoidance response in rats. Nature 233:211212. CrossRef Medline

McConnell JV (1962) Memory transfer through cannibalism in planarium. J Neuropsychiatr 3 [Suppl 1]:542-548.

McConnell JV (1965) The worm returns: the best from the Worm Runner's Digest. Upper Saddle River, NJ: Prentice-Hall.

Oberheim NA, Takano T, Han X, He W, Lin JH, Wang F, Xu Q, Wyatt JD, Pilcher W, Ojemann JG, Ransom BR, Goldman SA, Nedergaard M (2009) Uniquely hominid features of adult human astrocytes. J Neurosci 29:3276-3287. CrossRef Medline

Pribram KH (1969) The neurophysiology of remembering. Sci Am 222:7387. Medline

Pribram KH, Carlton EH (1986) Holonomic brain theory in imaging and object perception. Acta Psychol (Amst) 63:175-210. CrossRef Medline

Reinis S, Kolousek J (1968) Effect of methionine sulphoximine on memory transfer. Nature 217:680-681. CrossRef Medline

Rosenblatt F, Farrow JT, Herblin WF (1966) Transfer of conditioned responses from trained rats to untrained rats by means of a brain extract. Nature 209:46-48. CrossRef Medline

Sejnowski TJ (2015) Vernon Mountcastle: father of neuroscience. Proc Natl Acad Sci U S A 112:6523-6524. CrossRef Medline

Society for Neuroscience (2018) The creation of neuroscience, Society for Neuroscience. Available through open access on the $S f \mathrm{~N}$ website: https://www.sfn.org/About/History-of-SfN/1969-1995.

Ungar G, Irwin LN (1967) Transfer of acquired information by brain extracts. Nature 214:453-455. CrossRef Medline

Ungar G, Ocequera-Navarro C (1965) Transfer of habituation by material extracted from brain. Nature 207:301-302. CrossRef Medline

Yaremko RM, Hillix WA (1973) Reexamination of the biochemical transfer of relational learning. Science 179:305-306. CrossRef Medline 